\title{
CLINICAL EVALUATION OF MULTISURFACE ART RESTORATIONS
}

\author{
AVALIAÇÃO CLÍNICA DE RESTAURAÇÕES COMPOSTAS OU COMPLEXAS \\ COM A TÉCNICA DO ART
}

Daniela Francisca Gigo CEFALY ${ }^{1}$, Terezinha de Jesus Esteves BARATA ${ }^{2}$, Celiane Mary Carneiro TAPETY ${ }^{3}$, Eduardo BRESCIANI ${ }^{2}$, Maria Fidela de Lima NAVARRO ${ }^{4}$

\author{
1- DDS, MSc, PhD, Assistant Professor, Department of Dentistry, UNOPAR \\ 2- DDS, MSc, PhD, Graduate Student (Doctor degree), Department of Dentistry, Bauru Dental School - USP. \\ 3- DDS, MSc, PhD, Assistant Professor, Department of Dentistry, Federal University of Para. \\ 4- DDS, PhD, Associate Professor, Department of Operative Dentistry, Bauru Dental School - USP. \\ Corresponding address: Maria Fidela de Lima Navarro - Faculdade de Odontologia de Bauru - USP / Diretoria / Alameda Dr. Octávio Pinheiro \\ Brisolla 9-75 / Cep.: 17012-901 - Bauru-SP Phone: 142358295 - Fax: 142234679 - E-mail: mflnavar@usp.br \\ Received: December 12, 2003 - Modification: October 19, 2004 - Accepted: January 06, 2005
}

\begin{abstract}
The

Le aim of this study was to evaluate the performance of two different glass-ionomer cements: a high-density (Ketac Molar - ESPE) and a resin-modified cement (Fuji VIII - GC) using the Atraumatic Restorative Treatment technique to restore multisurface cavities in permanent teeth. A total of 60 ART restorations (30 with each material) were placed in schoolchildren (9-16 years of age) by two operators. After a period of 6 months, two independent examiners evaluated 59 restorations according to the criteria used in previous ART studies. Data were submitted to McNemar and Fischer tests. The success rate of the treatment was $98.3 \%$. One restoration (Ketac Molar) was replaced by another material and was recorded as failure. The success rates of the restorations were $100 \%$ and $96.6 \%$ for Fuji VIII and Ketac Molar, respectively. There was no statistically significant difference in the restorations success between baseline and 6 months ( $>0.05)$. In the same way, no significant differences were found between materials, cavity types or operators ( $>>0.05)$. The ART approach was highly appropriate and effective in restorations involving two or more tooth surfaces, after 6 months. The results showed a promising performance of the ART technique with both materials.

Uniterms: Glass ionomer cements; Atraumatic Restorative Treatment.
\end{abstract}

\section{RESUMO}

objetivo deste estudo foi avaliar o comportamento de dois cimentos de ionômero de vidro: um de alta viscosidade (Ketac Molar - ESPE) e um modificado por resina (Fuji VIII - GC) em restaurações envolvendo duas ou mais superfícies dentárias, confeccionadas pela técnica do Tratamento Restaurador Atraumático. Sessenta restaurações (30 com cada material) foram inseridas em estudantes (9-16 anos) por dois operadores. Após 6 meses, dois examinadores independentes avaliaram as restaurações de acordo com os critérios utilizados em trabalhos prévios semelhantes. Os dados foram analisados pelos testes de McNemar e Fischer. A porcentagem de sucesso do tratamento foi de 98,3\%. Uma restauração (Ketac Molar) foi substituída por outro material e classificada como falha. As porcentagens de sucesso das restaurações foram de 100\% e 96,6\% para o Fuji VIII e Ketac Molar, respectivamente. Não houve diferença estatisticamente significante no sucesso das restaurações entre o baseline e 6 meses ( $>>0,05)$. Da mesma forma, não houve diferença estatística entre os materiais, tipos de cavidade ou entre operadores.(p>0,05). A técnica ART foi altamente apropriada e efetiva em restaurações envolvendo duas ou mais superfícies, após 6 meses. Os resultados mostraram um comportamento promissor com ambos os materiais.

Unitermos: Cimentos de ionômero de vidro; Tratamento Restaurador Atraumático. 


\section{INTRODUCTION}

Since its development as part of a community-based primary oral health program carried out in Tanzania in the mid-1980s, the Atraumatic Restorative Treatment (ART) technique has been used around the world ${ }^{3,11,13,16,18}$. Such approach consists of caries removal using hand instruments only, followed by restoration of the prepared cavity with adhesive filling material, currently a glass-ionomer cement $(\mathrm{GIC})^{8}$.

The advantages of ART include the use of easily available and inexpensive hand instruments rather than the more expensive electrically-driven dental equipment, sound tooth tissue conservation due to the chemical adhesion of glassionomers, limitation of pain, minimizing the use of local anesthesia, and low cost. Due to these features, many people living in less developed areas can receive oral care through ART. In addition, it is also suitable for patient with permanent or temporary physical disabilities ${ }^{4}$.

Studies have shown high success percentage rate for one surface ART restorations $6,7,11,13$. However, very few studies have reported the success rates for multisurface restorations, mainly in permanent teeth. After one year, one study of an early GIC reported a success rate of $67 \%{ }^{9}$. More recently, Holmgren, et al. ${ }^{11}$ (2000) found approximately $90 \%$ and $80 \%$ success for Class I restorations involving two or more tooth surfaces and Class II restorations, respectively.

Initially, conventional GIC were used in ART clinical trials. After, high-density GIC were specially developed for ART use and they substituted the conventional ones,10,11,12. In 1997, Ewoldsen, Covey, Lavin ${ }^{2}$ suggested the use of resinmodified glass-ionomer luting cements in ART. The authors tested luting ionomers in increased powder/liquid ratio for restorative consistency and found higher diametral tensile and bond strengths than the conventional one. Although resin-modified GIC have shown better mechanical properties than conventional ${ }^{14,15,19}$, only one ART study evaluating such type of material in permanent teeth was found in literature ${ }^{18}$. Souza, et al. ${ }^{18}$ (2003) found higher success rate of Class II ART restorations in permanent teeth than other authors that used conventional GIC.

Therefore, the aim of this study was to evaluate the performance of two different glass-ionomer cements: a highdensity and a resin-modified cement using the Atraumatic Restorative Treatment technique to restore multisurface cavities in permanent teeth.

\section{MATERIALAND METHODS}

The study was carried out in suburban public schools of Bauru, in the northwest of São Paulo, Brazil. Ethical approval was obtained from the Ethics Committee of the Bauru Dental School. Sixty children aged 9 to 16 years presenting carious lesions involving two or more surfaces in posterior permanent teeth were included in the project. The exclusion criteria were teeth with pulpal exposure, a history of pain, or the presence of a swelling or fistula ${ }^{16}$.
During the selection of the subjects, the name, address, age, school, and medical and dental history were obtained. The subjects were included in the study only after parental or guardian consent with the respective signature on the consent form.

The working team consisted of two operators, both $\mathrm{PhD}$ students of the Bauru Dental School, and one chairside assistant. Prior to applying the technique in the field, operators and assistant had undergone a two-day instruction period.

Treatment was carried out inside classrooms at the schools selected to be part of the trial. Patients were positioned on a table combined with a foldable cushion and a soft headrest in order to achieve a proper patient-tooperator position. Since suction of saliva was not available for the ART procedure, cotton rolls were used to isolate the tooth. The tooth surface was cleaned with a wet cotton pellet for removal of debris and plaque. Cavity access was achieved with the use of enamel hatchet. The next step was removal of decalcified tissue with an excavator, first at the dentin-enamel junction and then from the floor of the cavity. The cavity was then cleaned with water on a small cotton pellet and dried with dry cotton pellet. When necessary, pulpal protection with calcium hydroxide cement (Hydro C - Dentsply) was used in deep cavities. The conditioning of the tooth structure was carried out with a cotton pellet saturated with Dentin Conditioner for Fuji VIII (GC Corp., Tokyo, Japan) or the liquid component of the material for Ketac Molar (ESPE, Seefeld, Germany) for about 10 seconds. The conditioned surfaces were then washed several times with wet cotton pellets and dried with dry cotton pellets. When restoring approximal surfaces, matrix strips and wedges were used. The glass-ionomer cements used were Ketac Molar (conventional high-density GIC) and Fuji VIII (resin-modified GIC). The manipulation and mixing of glass ionomer cements were carried out according to manufacturer's instructions. The selection of material for restorations was done in a randomized manner. The filling material was inserted into the cavity using an applicator and plugged into the corners of the cavity with the smooth side of an excavator. The material was also placed over the previously conditioned pits and fissures. Petroleum jelly was used to coat the operator's gloved finger and a slight pressure was applied on top of the entire occlusal surface for approximately 30 seconds. Any excess material was removed with a carver and the bite was checked using an articulating paper. Two coats of varnish (Copalite, Cooley \& Cooley, Houston, USA) were applied over the restoration to prevent cracks and the patient was instructed not to eat for at least one hour. Local anesthesia was used in 4 treatments.

A total of 60 fillings (30 for each material) were placed in 60 individuals After a period of 6 months, 59 patients were present and 59 restorations were evaluated. Two independent examiners evaluated the restorations according to the criteria used in previous ART studies ${ }^{3,5,9,7,12,13,16}$ (Table 1).

McNemar test was used to assess statistical significant 
differences between evaluation periods (baseline and 6 months). Fischer test was used for comparisons between materials, between operators and between cavity types. A difference was considered to be statistically significant if $\mathrm{p}<0.05$. Inter-examiner agreement was assessed with kappa statistics.

\section{RESULTS}

The mean age of the children at baseline was 11.59 years $(\mathrm{SD}=1.59)$. The mean DMFT was 3.48 ( $\mathrm{SD}=1.77)$, of which $82 \%$ teeth were decayed. Restorations were placed in Class I involving two or more tooth surfaces and Class II cavities (Table 2). Local anesthesia was necessary in 4 treatments. In 12 deep cavities a thin layer of calcium hydroxide was

TABLE 1- Codes used in the evaluation of the ART restorations

\begin{tabular}{ll}
\hline Score & \multicolumn{1}{c}{ Description } \\
\hline 0 & Present, in good condition \\
1 & Present, slight marginal defect, no repair is needed \\
2 & Present, slight wear, no repair is needed \\
3 & Present, marginal defect $>0.5 \mathrm{~mm}$, repair is needed \\
4 & Present, wear $>$ 0.05 mm, repair is needed \\
5 & Not present, restoration partly or completely missing \\
6 & Not present, restoration replaced by another restoration \\
7 & Tooth is missing, exfoliated or extracted \\
8 & Restoration not assessed, child is nor present \\
\hline
\end{tabular}

Codes: $0,1,2$ = successful; 3, 4, 5, 6 = failure;

$7,8=$ excluded applied over the deep spots.

At 6-month evaluation one restoration (Ketac Molar) was not examined as the child was absent. Table 3 shows the status of the ART restorations at the 6-month evaluation by Class type. One restoration (Ketac Molar) was replaced by another material and was recorded as failure. The success rates of the restorations were $100 \%$ and $96.6 \%$ for Fuji VIII and Ketac Molar, respectively. The success rate of the treatment was $98.3 \%$.

There was no statistically significant difference in the restorations success between baseline and 6 months ( $p>0.05$ ). In the same way, no significant differences were found between materials, cavity types or operators ( $\mathrm{p}>0.05)$. Interexaminer reproducibility was very good $($ Kappa $=1.00)$.

\section{DISCUSSION}

Most of the ART studies has evaluated restorations in Class I cavities and has shown high success rate, ranging from $93 \%-99 \%$ in the first year of evaluation ${ }^{6,7,11,13}$. However, few studies in the literature have evaluate the performance of ART restorations in cavities involving two or more tooth surfaces ${ }^{9,11,18}$. In these situations, usually, the cavity is quite deep and pulpal involvement can happen at any moment. For the majority of people living in less developed areas the treatment provided in these cases is the extraction. In the present study such type of cavities was selected aiming to avoid extraction, once a considerable number of extractions was observed in previous ART studies conducted in suburban schools of Bauru.

The treatment success rate was $98.3 \%$. Regarding to cavity type, $100 \%$ of Class I restorations was considered successful for both materials. For Class II, the success rates were $100 \%$ for Fuji VIII and 92\% for Ketac Molar. Frencken, et al. ${ }^{9}$ evaluated 18 restorations involving two or more tooth surfaces after 1 year and found lower success rate (67\%)

TABLE 2- Distribution of restorations according to Class type

\begin{tabular}{|c|c|c|c|c|}
\hline & \multicolumn{2}{|c|}{ Class I } & \multicolumn{2}{|c|}{ Class II } \\
\hline & Ketac Molar & Fuji VIII & Ketac Molar & Fuji VIII \\
\hline Number of restorations & 17 & 19 & 13 & 11 \\
\hline Total & \multicolumn{2}{|c|}{36} & \multicolumn{2}{|c|}{24} \\
\hline
\end{tabular}

TABLE 3- Status of the ART restorations after 6 months

\begin{tabular}{|c|c|c|c|c|c|c|c|c|}
\hline & \multicolumn{4}{|c|}{ Class I } & \multicolumn{4}{|c|}{ Class II } \\
\hline & \multicolumn{2}{|c|}{ Ketac Molar } & \multicolumn{2}{|c|}{ Fuji VIII } & \multicolumn{2}{|c|}{ Ketac Molar } & \multicolumn{2}{|c|}{ Fuji VIII } \\
\hline Codes & $\mathrm{n}$ & $\%$ & $\mathrm{n}$ & $\%$ & $\mathrm{n}$ & $\%$ & $\mathrm{n}$ & $\%$ \\
\hline 0 - success & 16 & 100 & 19 & 100 & 12 & 92 & 11 & 100 \\
\hline \multirow[t]{2}{*}{6 - failure } & 0 & 0 & 0 & 0 & 1 & 8 & 0 & 0 \\
\hline & 16 & 100 & 19 & 100 & 13 & 100 & 11 & 100 \\
\hline
\end{tabular}


than the present study. The higher success rate of the present study is probably due to improvements in the ART approach combined with the use of high strength glassionomers. Holmgren, et al. ${ }^{11}$ found more promising results, with success rate of $90 \%$ for "large" Class I and approximately $80 \%$ for Class II restorations, in the first year. The authors considered "large" the cavities extending over more than half the tooth surface either in a mesio-distal or bucco-lingual direction or involving more than one tooth surface. Nevertheless, the success of the present study was higher, mainly for Class II restorations. Although the found results are satisfactory, further clinical evaluations after longer periods are necessary, because the ART studies have shown a decrease in the success rate of restorations over the years ${ }^{5,7,13,16}$.

In earlier studies, conventional GIC were used w $^{5,9,13,16}$ After, high-density GIC specifically developed for ART substituted the conventional ones, ${ }^{6,11,12}$. The development of resin-modified GIC resulted in better mechanical properties of these materials than the conventional GIC ${ }^{14,15,19}$. Consequently, Ewoldsen, Covey, Lavin ${ }^{2}$ suggested the use of resin-modified GIC in ART aiming higher success rate of the restorations. The authors tested resin-modified glassionomer luting cement at increased powder/liquid ratio for restorative consistency and observed higher diametral tensile and shear bond strengths of these materials than the conventional. However, only one ART study evaluated resinmodified GIC in permanent teeth ${ }^{18}$. Souza, et al. ${ }^{18}$ found $86.7 \%$ success rate for Class II restorations with Fuji Plus, after 8 months. The results were better than those found in other researches with conventional GIC, in the same cavity type $\mathrm{e}^{9,11}$. The higher success rate found in the present study may be related to the materials which were different from that used by Souza, et al..$^{18}$ and/or to the technique, once there was no significant difference between the materials performance.

Although the present work is a short-term study, data are significant because ART literature is scarce in both: studies evaluating resin-modified GIC and multisurface restorations. Resin-modified glass-ionomers for cementing application were suggested for ART because they are chemically activated rather than photo-activated. However, a restorative resin-modified GIC indicated for anterior teeth, Fuji VIII (GC), is now available on market. Such material was chosen because it have presented higher diametral tensile and bond strengths than Ketac Molar (ESPE) $)^{1,20}$. On the other hand, there was no significant difference in the materials performance in the present short-term clinical trial.

Evaluation criteria used are based on previous similar ART studies $3,5,9,7,12,13,16$. One restoration (Ketac Molar) was replaced by another material (intermediate restorative material) and was recorded as failure. The child's mother related that about 4 months after the treatment the patient felt pain. So, patient looked for a Public Health Center where pulp extirpation was done. At evaluation period, patient was directed to Bauru Dental School where endodontic treatment was provided.

Unfortunately, ART is not suitable for all the types of carious lesions. Exclusion criteria are teeth with pulpal exposure, history of pain, or the presence of swelling or fistula. However, sometimes diagnosis is difficult because the pain is a subjective subject. Besides, due to the x-ray absence, it is not possible to predict the lesion depth. In this case, a previous pulpal involvement could have existed and the treatment contributed to accelerate an irreversible pulpitis.

Carious lesions located on approximal surfaces of posterior teeth are a challenge to the ART operator. Access to the lesion is sometimes difficult without a bur and the saliva contamination is hard to control in the cervical area. Besides, caries removal was difficult in some areas such as beneath cusps and at dentine-enamel junction. In these cases, the improved design of Carisolv ${ }^{\mathrm{TM}}$ excavators become caries removal easier.

An important aspect to be considered in the success of the treatment is the presence of a chairside assistant. In the present study, an assistant was responsible for the manipulation of the materials. In this way, the operators could better control the relative isolation, avoiding the contamination of the prepared cavity with saliva. Safar, Davis, Overton ${ }^{17}$ verified that salivary contamination adversely affected the adhesion of glass-ionomer cements to dentin. Rinsing and re-etching the dentin failed to result in strength as great as to noncontaminated dentin.

A program including diet and oral hygiene instructions as well as ART treatment should be adopted in schools of underprivileged communities. Such program could provide oral assistance for people from the childhood to the adolescence and contribute to prevention, reduction and even eradication of caries disease.

The ART approach was highly appropriate and effective in restorations involving two or more tooth surfaces, after 6 months. The results showed a promising performance of the ART technique with both materials.

\section{ACKNOWLEDGEMENTS}

This study was supported by FAPESP - Fundação de Amparo à Pesquisa do Estado de São Paulo - (Grant\# 01/ 04943-0).

\section{REFERENCES}

1- Cefaly, DFG, Tapety, CMC, Barata, TJE, Mondelli RFL, Bresciani E, Navarro MFL. Tensile bond strength of glass-ionomer cements used in Atraumatic Restorative Treatment to demineralized enamel [abstract n.1446]. J Dent Res 2003;82(sp. Issue):B-193.

2- Ewoldsen N, Covey D, Lavin M. The physical and adhesive properties of dental cements used for atraumatic restorative treatment. Spec Care Dent 1997;17:19-24.

3- Frencken JE, Borsun-Anderson K, Makoni F, Moyana F, Mwashaenyi S, Mulder J. Effectiveness of an oral health education programme in primary schools in Zimbabwe after 3.5 years. Community Dent Oral Epidemiol 2001;29:253-9.

4- Frencken JE, Holmgren CJ. Atraumatic restorative treatment for dental caries. Nijmegen: STI Book b.v., 1999. 
5- Frencken JE, Makoni E, Sithole WD. Atraumatic restorative treatment and glass-ionomer sealants in a oral health programme in Zimbabwe: evaluation after 1 year. Caries Res 1996; 30:428-33.

6- Frencken JE, Makoni E, Sithole WD. ART restorations and glass ionomer sealants in Zimbabwe: survival after 3 years. Community Dent Oral Epidemiol 1998;26:372-81.

7- Frencken JE, Makoni F, Sithole WD, Hackenitz E. Three-year survival of one-surface ART restorations and glass-ionomer sealants in a school oral health programme in Zimbabwe. Caries Res 1998;32:119-26.

8- Frencken JE, Pilot T, Songpaisan Y, Phantumvanit P. Atraumatic restorative treatment (ART): rationale, technique, and development. J Public Health Dent 1996;56:135-40.

9- Frencken JE, Songpaisan Y, Phantumvanit P, Pilot T. An atraumatic restorative treatment (ART) technique: evaluation after one year. Int Dent J 1994;44:460-4.

10- Ho TFT, Smales RJ, Fang DTS. A 2-year clinical study of two glass ionomer cements used in the atraumatic restorative treatment (ART) technique. Community Dent Oral Epidemiol 1999;27:195201

11- Holmgren CJ, Lo ECM, Hu DY, Wan HC. ART restorations and sealants placed in Chinese school children - results after three years. Community Dent Oral Epidemiol 2000;28:314-20.

12- Lo ECM, Holmgren CJ. Provision of atraumatic restorative treatment (ART) restorations to Chinese pre-school children - a 30month evaluation. Int J Paed Dent 2001;11:3-10.

13- Mallow PK, Durward CS, Klaipo M. Restoration of permanent teeth in young rural children in Cambodia using the atraumatic restorative treatment (ART) thechnique and Fuji II glass ionomer cement. Int J Paediatr Dent 1998;8:35-40.

14- Mathis RS, Ferracane JL. Properties of a glass-ionomer/resincomposite hybrid material. Dent Mater 1989;5:355-8.

15- McCarthy MF, Hondrum SO. Mechanical and bond strength properties of light-cured and chemically cured glass ionomer cements. Am J Orthod Dentofac Orthop 1994;105:135-41.

16- Phantumvanit P, Songpaisan Y, Pilot T, Frencken, JE. Atraumatic restorative treatment (ART): a three-year community field trial in Thailand - survival of one surface restorations in the permanent dentition. J Public Health Dent 1996; 56:141-145.

17- Safar JA, Davis RD, Overton JD. Effect of saliva contamination on the bond of dentin to resin-modified glass-ionomer cement. Oper Dent 1999;24:351-57.

18- Souza EM, Cefaly, DFG, Terada, RSS, Rodrigues CC, Navarro MFL. Clinical evaluation of the ART technique using high density and resin-modified glass ionomer cements. Oral Health Prev. Dent 2003;3:201-7

19- Uno S, Finger WJ, Fritz U. Long-term mechanical characteristics of resin-modified glass ionomer restorative materials, Dent Mater 1996;12:64-6

20- Vono HZ, Cefaly, DFG, Tapety, CMC, Navarro MFL. Resistência à tração diametral de três cimentos de ionômero de vidro indicados no ART [abstract n.Pb217]. Pesq Odontol Bras 2003; 17(supplement 2):186. 